\title{
Surface Roughness of Bulk Fill Composite after Simulated Toothbrushing with Different Dentifrices
}

\author{
Ahmed Mohamed Elmarakby ${ }^{1,2 *}$, Mahmoud Darwish ${ }^{3,4}$, Yasser R Souror ${ }^{5,6}$, Ahmed Waly ${ }^{5,7}$ \\ ${ }^{1}$ Department of Restorative Dental Sciences, Al-Farabi College for Dentistry and Nursing, Riyadh, KSA; ${ }^{2}$ Department of \\ Operative Dentistry, Faculty of Dental Medicine, Al-Azhar University, Assiut, Egypt; ${ }^{3}$ Department of Prosthetic Dental Sciences, \\ Al-Farabi College for Dentistry and Nursing, Riyadh, Saudi Arabia; ${ }^{4}$ Department of Prosthodontics, Faculty of Dentistry, Suez \\ Canal University, Ismailia, Egypt; ${ }^{5}$ Department of Pediatric Dentistry and Dental Public Health, Faculty of Dentistry, Al-Azhar \\ University, Assiute. Egypt; ${ }^{6}$ Department of Pediatric Dentistry, Batterjee Medical College, Jeddah, KSA; ${ }^{7}$ Department of Pediatric \\ Dentistry, AlFarabi Dental College, Jeddah, Saudi Arabia
}

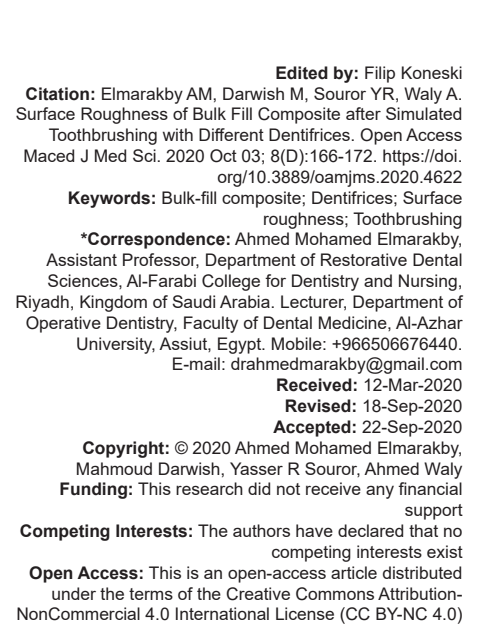

\section{Abstract}

AIM: The aim of the current in vitro study was to evaluate the changes in surface roughness of bulk fill composites after simulated toothbrushing with different dentifrices.

MATERIALS AND METHODS: Three types of bulk fill resin composites were used in this study; 27 specimens of each composite resin were randomly divided into three main groups $(n=9)$. Each main group was further subdivided into three subgroups $(n=3)$. Each group was subjected to simulated toothbrushing with three different dentifrices. One-way analysis of variance was used to evaluate the effect of brushing using dentifrices on the surface roughness of each type of composite resin, followed by Tukey's test at a significance level of $p \leq 0.5 \%$.

RESULTS: Results revealed that different effects on composite surface roughness were detected after simulating toothbrushing with different dentifrices. Lacalut toothpaste abrades more with Filtek Bulk Fill, Tetric N-Ceram then Bulk Fill SDR. Crest 3D toothpaste abrades more with Tetric N-Ceram, Bulk Fill SDR then Filtek Bulk Fill. BlanX toothpaste abrades more with Tetric N-Ceram, Bulk Fill SDR then Filtek Bulk Fill.

CONCLUSION: Chemical composition of both resin composites and dentifrices plays an important role in influencing the degree of surface roughness of bulk fill composite resin restorations.

\section{Introduction}

The drawbacks of amalgams, in particular the lack of esthetics and presence of mercury have largely contributed to the popularity and increased use of resinbased composites (RBCs) for tooth restorations [1]. The RBCs have undergone tremendous research and development in the last 40 years to improve their performance, mechanical properties, and clinical handling [2]. These developments have primarily focused on improving the mechanical properties such as hardness, compressive strength, flexural strength, fracture toughness, and reducing polymerization shrinkage [3]. Bulk-fill composite resin is among the recent development in dental composites. These types of resin composite can be placed in a $4 \mathrm{~mm}$ thick bulk in the cavities and cured in one step instead of the current incremental fill technique where the increments of $2 \mathrm{~mm}$ is placed and cured [4]. Bulkfill composite seems to improve the bad effect of the polymerization shrinkage, improve the cavity adaptation, and degree of conversion (DC \%). It was also reported that bulk fill composites have superior physical and mechanical properties to resist high masticatory forces in oral cavity [5], [6]. Many studies have focused on the mechanical properties of the bulk-fill composites [4], [6], [7], [8] and there were little literatures focused on the behavior of these composites when subjected to tooth brush abrasion. Like enamel and dentin [9], restorative materials are also subjected to wear especially in the posterior occlusal surfaces. The degree of wear depends on the type of restorative material [8], [9]. The wear and abrasion of the restorative materials in the oral environment can be a result of different factors. These include direct contact between the tooth and the restorations during mastication, oral habits, toothbrushing with abrasive particles, and also due to chemicals in the dietary form [10]. The wear and abrasion can lead to an adverse effect on the mechanical properties of the materials and also leads to an increased surface 
roughness [11]. The surface roughness may increase the coefficient of friction and the rate of wear [12]. Rough surface can also predispose for accumulation of dental biofilms, residues, and stains that may lead to gingival irritation, risk of secondary caries, diminishing the gloss of the restoration, and giving rise to discoloration and/or surface degradation [13], [14]. Despite the fact that toothbrushing plays an important role in oral hygiene, their ongoing action might damage the surface of resin composite restoration, making it rougher and consequently prone to staining, plaque accumulations, soft tissue inflammation, and recurrent caries [15], [16]. The amount of wear caused by toothbrushing depends mainly on toothbrushing habits, type of the tooth brush (hard, medium, or soft), and the dentifrice abrasive material used [17]. The toothbrushing abrasion that causing changes in surface conditions of restorative materials in any experimental situations can be helpful in predicting the clinical behavior of such materials [18]. The wear and surface roughness may also have a negative impact on the longevity of the restoration in the oral environment. The surface roughness of the composite is usually dictated by size, hardness and quantity of particles load which influence the mechanical properties of composites [19]. Dentifrices have different components such as detergents, fluoride, therapeutic ingredients, flavors, and abrasives. Among the abrasives, the most common are calcium carbonate and silica [20]. These abrasives have an important role in cleaning teeth, removing bacteria and stains from the tooth surface. However, the best dentifrices material should promote optimal tooth surface cleaning with minimal abrasive action [21]. Dentifrices with high amounts of abrasives can damage hard tissues, soft tissues, and restorations causing gingival recession, cervical abrasion, dentin hypersensitivity, and increased surface roughness of restorative materials [22], [23]. Some studies have been conducted to evaluate the surface roughness of composite resins caused by the abrasivity of some dentifrices. Amaral et al. [24] evaluated the action of abrasive dentifrices on esthetic restorative materials after simulated toothbrushing cycles. They found a significant difference between the abrasivity of dentifrices, but not among the composite resins. The dentifrices that used silica and carbonate were less abrasive compared to the ones containing bicarbonate. Some studies [25], [26] have shown that the surface roughness of composite resins has a direct influence on susceptibility to staining and need for restoration replacement. Others have reported no correlation between surface roughness and staining susceptibility [6], [27]. Hence, it becomes necessary to study the effect of toothbrushing on composite wear and roughness. The aim of the current in vitro study was to evaluate the changes in surface roughness of bulk fill composites after simulated toothbrushing with different dentifrices.

\section{Materials and Methods}

Before starting this in vitro study, the ethical approval was obtained from the Scientific Research Unit of Al-Farabi College for Dentistry and Nursing. The research proposal was approved by Institutional Review Board (IRB) at Al-Farabi College for Dentistry and Nursing in Riyadh, Saudi Arabia under no. (IRB No.: Alf. dent-2020023).

\section{Selection of composite resin}

Three types of resin composites were used in this in vitro study. Selection criteria for the composite brands include that they could be of bulk fill category with same curing time and same depth of cure.

1. The Bulk Fill SDR Posterior Bulk Fill Flowable Based composite (Dentsply Caulk 38 West Clarke Avenue Milford, DE 19963, USA).

2. Tetric N-Ceram Bulk Fill (Ivoclar Vivadent AG Bendererstrasse 2. FL-9494 Schaan Principality of Liechtenstein).

3. Filtek Bulk Fill Posterior Restorative (3M, ESPE, Elipar, Filtek Scotchbond. Canada).

The specifications of each composite resin brand are described in Table 1.

The composite resin specimens were made using a silicone matrix with orifices of $5 \mathrm{~mm}$ in diameter and height. The matrix was positioned on a glass plate and filled with composite resin. A polyester strip was then placed on the composite resin followed by a glass plate to obtain a flat surface. The composite resin was then light cured with the light emitting diode unit Radii-cal (SDI, Australia) for $20 \mathrm{~s}$ at a distance of $1 \mathrm{~mm}$ from the surface of the specimen. Toothbrushing with dentifrices was applied on the composite resin surface that was in contact with the polyester strip. Twenty-seven specimens

Table 1: Specifications and manufacturers of bulk fill resinbased composites

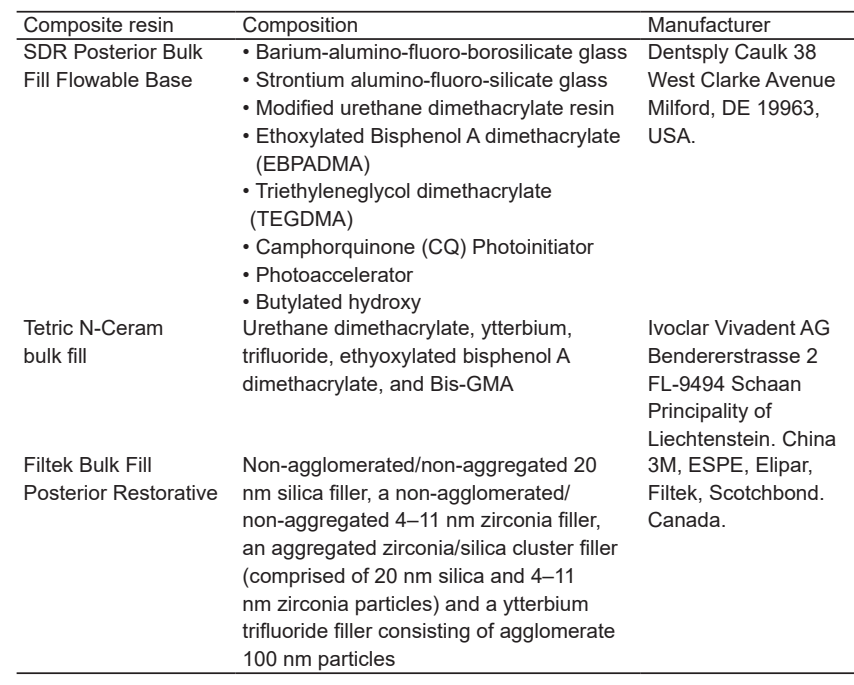


of each resin composite type where fabricated and stored in distilled water at room temperature for $24 \mathrm{~h}$ to complete the polymerization and simulate conditions of the oral cavity environment.

\section{Experimental groups}

The 27 specimens of each composite resin were randomly divided into three main groups $(n=9)$. Each main group was further subdivided into three subgroups $(n=3)$. Each group was subjected to simulated toothbrushing with three different dentifrices: BlanX sensitive teeth toothpaste, Crest 3D white Brilliance toothpaste, and Lacalut aktiv medical toothpaste. The composition of each dentifrice is listed in Table 2.

\section{Evaluation of surface roughness}

The initial surface roughness of each specimen was measured with a contact profilometer device (MarSurf PS1-Mahr GmbH. GÖttingen-Germany). Three consecutive measurements of the specimen were taken in different regions (one central, one right, and one left) for obtaining the mean average from the three measurements. The roughness of the surfaces was measured again after surfaces of resin composites subjected to simulated toothbrushing.

\section{Simulated toothbrushing}

The simulated toothbrushing was done manually by one operator using (Oral-B 40) rotary toothbrushing machine. This is done throughout the experiment to ensure proper standardization and decrease variables. Operator's errors were avoided by excluding any major changes in readings. Each specimen was fixed in the center (orifice) of an acrylic plate $(55 \mathrm{~mm} \times 25 \mathrm{~mm} \times$ $4 \mathrm{~mm}$ ), respectively, for the diameters and height, enabling the test surface to remain $1 \mathrm{~mm}$ beyond the edge of the orifice which housed the specimen. Utility wax was applied to fix the specimens. Each plate was placed in an acrylic tank which was attached to the brushing machine by metal pins. The acrylic tank was filled with a mixture composed of $1 \mathrm{~g}$ of dentifrice paste per $1 \mathrm{ml}$ of distilled water. Medium bristle classic rotary toothbrush was used for simulated toothbrushing that continued once daily for approximately 6 months. The dentifrice pastes were changed every cycle. Rotary toothbrushes were changed every 6 days. After every brushing cycle, the specimens were washed in running tab water, cleaned in distilled water for 10 min and drying with compressed air. The roughness of the surface was measured again. Surface roughness readings were measured perpendicular to the brushing direction of the rotary toothbrush bristles. For the correct positioning of the specimen in the brushing machine and to always ensure readability in the same direction (perpendicular to the brushing), a mark with a diamond bur mounted in a high-speed hand piece was made on the border of each specimen.

\section{Statistical analysis}

The values of surface roughness were collected, organized, and tabulated. One-way analysis of variance was used to evaluate the effect of brushing using dentifrices on the surface roughness of each type of composite resin, followed by Tukey's test at a significance level of $p \leq 0.5 \%$.

\section{Results}

Results revealed that different effects on composites surface roughness were detected after simulating toothbrushing with different dentifrices. Regarding The Bulk Fill SDR Posterior Bulk Fill Flowable Based composite (Dentsply) results revealed that the mean differences in surface roughness after simulating toothbrushing using different toothpastes were as follow: Lacalut toothpaste (0.33), Crest 3D White (0.39), and BlanX (0.58). There was no statistical significant difference between values of Lacalut toothpaste (0.33) and Crest 3D White (0.39), but there was a statistical significant difference between them and BlanX (0.58) as $\mathrm{p} \leq 0.5 \%$. Regarding Filtek Bulk Fill Posterior Restorative composite (3M, ESPE, E) results revealed that the mean differences in surface roughness after simulating toothbrushing were as follow: Lacalut toothpaste $(0.78)$, Crest 3D White (0.33), and BlanX (0.30). There was no statistical significant difference between values of

Table 2: Specifications and manufacturers of toothpastes

\begin{tabular}{|c|c|c|}
\hline Toothpaste & Composition & Manufacturer \\
\hline $\begin{array}{l}\text { BlanX Sensitive } \\
\text { Teeth Toothpaste }\end{array}$ & $\begin{array}{l}\text { Hydroxyapatite, Potassium Chloride, Sodium Fluoride, Arctic Lichen, Aqua, Glycerin, Hydrated Silica, Sorbitol, Potassium BlanX } \\
\text { Sensitive Chloride, Silica, PEG-32, Cellulose Gum, Zinc Hydroxyapatite, Xylitol, Cetraria islandica extract, Usnea barbata extract, } \\
\text { Eugenia Teeth Caryophyllus Flower Oil, Mentha Piperita Oil, Mentha Viridis Leaf Toothpaste Oil, Sodium Monofluorophosphate, } \\
\text { Sodium Myristoyl Sarcosinate, Sodium Methyl Cocoyl Taurate, Zinc Citrate, Sodium Fluoride, Sodium Saccharin, Menthol, Titanium } \\
\text { Dioxide, Benzyl Alcohol, Phenoxyethanol, Sodium Benzoate, Eugenol, Limonene. }\end{array}$ & Sensodyne, UAE \\
\hline $\begin{array}{l}\text { Crest 3D White } \\
\text { Brilliance }\end{array}$ & $\begin{array}{l}\text { Sodium fluoride } 0.243 \% \text {, glycerin, hydrated silica, sodium hexametaphosphate, water, PEG-6, flavor, trisodium phosphate, sodium } \\
\text { lauryl sulfate, carrageenan, cocamidopropyl betaine, sodium g saccharin, PEG-20M or PEG-23M, xanthan gum, sucralose, mica, } \\
\text { titanium dioxide. }\end{array}$ & $\begin{array}{l}\text { The Procter and Gamble } \\
\text { Manufacturing Company, USA }\end{array}$ \\
\hline $\begin{array}{l}\text { Lacalut Aktiv } \\
\text { Medical } \\
\text { Toothpaste }\end{array}$ & $\begin{array}{l}\text { Aqua, Hydrogenated Starch Hydrolysate, Aluminum Hydroxide, Lacalut Medical Hydrated Silica, Silica, Poloxamer } 188 \text {, Sodium } \\
\text { Lauryl Sulfate, Aroma, Hydroxyethyl cellulose, Aluminum Lactate, Titanium Dioxide, Toothpaste Allantoin, Aluminum Fluoride, Sodium } \\
\text { Saccharin, Chlorhexidine Digluconate, Bisabolol, Limonene. }\end{array}$ & Lacalut, China \\
\hline
\end{tabular}


Crest 3D White (0.33) and BlanX (0.30), but there was a statistical significant difference between them and Lacalut toothpaste $(0.78)$ as $p \leq 0.5 \%$. Regarding Tetric $\mathrm{N}$-Ceram bulk fill (Ivoclar Vivadent) results revealed that the mean differences in surface roughness after simulating toothbrushing were as follow: Lacalut toothpaste (0.59), Crest 3D White (0.81), and BlanX (0.81). There was no statistical significant difference between values of Crest 3D White (0.81) and BlanX (0.81), but there was a statistical significant difference between them and Lacalut toothpaste (0.59) as $p \leq 0.5 \%$. Regarding the effect of Lacalut toothpaste on the surface roughness of different bulk fill resin composites, results revealed that mean difference values vary according to type of composite used as follow: Bulk Fill SDR (0.33), Filtek Bulk Fill (0.78), and Tetric N-Ceram (0.59). These results are shown in Table 3.

Table 3: Effect of Lacalut toothpaste on surface roughness on the 3 types of composite

\begin{tabular}{|c|c|c|c|c|c|c|c|c|c|}
\hline \multirow[t]{2}{*}{ SDR } & \multicolumn{6}{|c|}{ Sample no. } & \multicolumn{2}{|c|}{ Mean } & \multirow[t]{2}{*}{ Difference } \\
\hline & 1 & & 2 & & 3 & & & & \\
\hline \multirow[t]{2}{*}{$\begin{array}{l}\text { SDR } \\
\end{array}$} & Pre & 0.270 & Pre & 0.391 & Pre & 0.697 & Pre & 0.45 & 0.33 \\
\hline & Post & 0.856 & Post & 0.594 & Post & 0.894 & Post & 0.78 & \\
\hline \multirow[t]{2}{*}{ Filtek Bulk Fill } & Pre & 0.741 & Pre & 0.408 & Pre & 0.493 & Pre & 0.54 & 0.78 \\
\hline & Post & 1.311 & Post & 1.780 & Post & 0.884 & Post & 1.32 & \\
\hline \multirow[t]{2}{*}{ Tetric N-Ceram } & Pre & 0.249 & Pre & 0.707 & Pre & 0.486 & Pre & 0.48 & 0.59 \\
\hline & Post & 1.027 & Post & 1.164 & Post & 1.021 & Post & 1.07 & \\
\hline
\end{tabular}

Regarding the effect of Crest 3D White toothpaste on the surface roughness of different bulk fill resin composites, results revealed that mean difference values were as follow: Bulk Fill SDR (0.39), Filtek Bulk Fill (0.33), and Tetric N-Ceram (0.81). These results are shown in Table 4.

Table 4: Effect of crest 3D white toothpaste on surface roughness on the 3 types of composite

\begin{tabular}{llllllllll}
\hline SDR & \multicolumn{3}{l}{ Sample no. } & & \multicolumn{3}{l}{ Mean } & & Difference \\
\cline { 2 - 6 } & 1 & & 2 & 3 & & & \\
\hline SDR & Pre & 0.278 & Pre & 0.589 & Pre & 0.339 & Pre & 0.40 & 0.39 \\
& Post & 0.731 & Post & 0.629 & Post & 1.038 & Post & 0.79 & \\
Filtek Bulk Fill & Pre & 0.600 & Pre & 0.530 & Pre & 0.419 & Pre & 0.51 & 0.33 \\
& Post & 0.745 & Post & 0.839 & Post & 0.957 & Post & 0.84 & \\
\multirow{2}{*}{ Tetric N-Ceram } & Pre & 0.511 & Pre & 0.279 & Pre & 0.619 & Pre & 0.46 & 0.81 \\
& Post & 1.843 & Post & 0.980 & Post & 1.000 & Post & 1.27 & \\
\hline
\end{tabular}

Regarding the effect of BlanX toothpaste on the surface roughness of different bulk fill resin composites, results were as follow: Bulk Fill SDR (0.58), Filtek Bulk Fill (0.30), and Tetric N-Ceram (0.81). These results are shown in Table 5.

Table 5: Effect of BlanX toothpaste on surface roughness on the 3 types of composite

\begin{tabular}{|c|c|c|c|c|c|c|c|c|c|}
\hline \multirow[t]{2}{*}{$\begin{array}{l}\text { SDR } \\
\end{array}$} & \multicolumn{6}{|c|}{ Sample no. } & \multirow{2}{*}{\multicolumn{2}{|c|}{ Mean }} & \multirow[t]{2}{*}{ Difference } \\
\hline & \multicolumn{2}{|l|}{1} & \multicolumn{2}{|l|}{2} & \multicolumn{2}{|l|}{3} & & & \\
\hline \multirow[t]{2}{*}{ SDR } & Pre & 0.213 & Pre & 0.313 & Pre & 0.399 & Pre & 0.3 & 0.58 \\
\hline & Post & 1.024 & Post & 0.780 & Post & 0.844 & Post & 0.88 & \\
\hline \multirow[t]{2}{*}{ Filtek Bulk Fill } & Pre & 0.249 & Pre & 0.607 & Pre & 0.504 & Pre & 0.45 & 0.30 \\
\hline & Post & 0.580 & Post & 0.640 & Post & 1.049 & Post & 0.75 & \\
\hline \multirow[t]{2}{*}{ Tetric N-Ceram } & Pre & 0.268 & Pre & 0.259 & Pre & 0.410 & Pre & 0.31 & 0.81 \\
\hline & Post & 1.129 & Post & 1.021 & Post & 1.215 & Post & 1.12 & \\
\hline
\end{tabular}

Statistical significant differences among all variables are summarized in Table 6 and illustrated in Figure 1.

Table 6: Differences (D) between variables

\begin{tabular}{llll}
\hline Toothpaste & Composite & & \\
\cline { 2 - 4 } & SDR & Filtek Bulk Fill & Tetric N-ceram \\
\hline Lacalut & 0.33 & 0.78 & 0.59 \\
Crest 3D white & 0.39 & 0.33 & 0.81 \\
BlanX & 0.58 & 0.30 & 0.81 \\
\hline
\end{tabular}

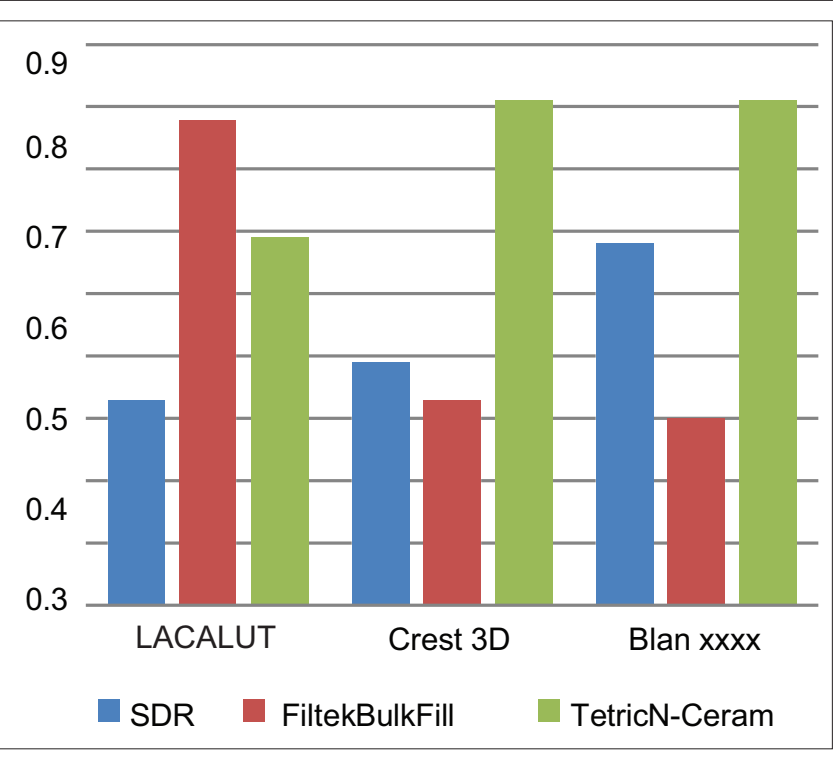

Figure 1: Bar chart showing statistical significant differences among all variables

\section{Discussion}

The present study evaluated the influence of toothbrushing abrasion on the surface roughness of three commercial bulk fill composite resins. Restorative material surfaces in the oral environment are subjected to various factors, which can modify the surface roughness. Toothbrushing using dentifrices is one of the oral hygiene procedures that play a significant role in reducing plaque and caries among other benefits. Previous studies have reported that amount of wear by toothbrush dentifrice abrasion depends on toothbrush quality, toothbrushing habits, type of dentifrices used, the load applied, slurry dilution, and oral temperature [28]. It is also reported that wear resistance of a composite depends mainly on shape, size, load of inorganic filler, and to little extent on the organic matrix components [29]. The mechanical characteristics of the composite resins can be evaluated by surface roughness measurements after they subjected to simulated toothbrushing [30]. In the present study, a medium type of rotary toothbrush was selected with different dentifrices and the results revealed statistical significant differences in the values of composite resin surface roughness. This result disagreed with the study of Oliveira et al. where they reported that toothbrush type did not affect the resin composite wear or surface roughness when used with a wet medium type [30]. In addition, some authors reported that soft type toothbrushes abrade more when compared to medium or hard types of brushes [31]. In the present study and regarding influences of surface roughness, a significant difference was observed among all groups of tested bulk fill resin composites. Results of the present study are in agreement of other studies that reported that Filtek Bulk Fill Posterior Restorative (3M, ESPE) are more resistant to wear and surface roughness than The Bulk Fill SDR Posterior 
and Bulk Fill Flowable Based composite (Dentsply). Although the mentioned later two types of composite fillers have same average cluster size, it is clear that the non-aggregated zirconia/silica cluster filler presented in Filtek Bulk Fill Posterior Restorative (3M, ESPE) can resist the toothbrushing abrasion more effectively than triethylene glycol dimethacrylate (TEGDMA) presented in Bulk Fill SDR (Dentsply) [32]. Notably, in the present study, the Tetric N-Ceram bulk fill (Ivoclar Vivadent) demonstrated more statistical significant differences in surface roughness compared to other two types of composites. This finding was in agreement with the results of Mitra et al. [33]. They clarified that urethane dimethacrylate (the main composition of Tetric N-Ceram bulk fill) showed less resistant to wear and surface roughness among the tested composite groups. This could be better explained due to the fact that mean distance between adjoining particles is less than coarse filler particles. This structure favors protection against wear of the matrix and ensures better performance of the material [34]. Quirynen and Bollen [35], [36] reported that surface roughness values in composite materials should be below $0.4 \mu \mathrm{m}$ to prevent adhesion of plaque and microorganisms. The roughness of the restoration can be detected by tongue if the surface roughness value is above $0.7 \mu \mathrm{m}$ [37]. In the current study, the initial Ra values of all the tested composites were around the threshold limit of $0.4 \mu \mathrm{m}$ but after final brushing cycles, most of the tested groups exhibited values above $0.7 \mu \mathrm{m}$. Although the filler loading in all types of composites used in this study was $82 \%$ by weight, it was clear that chemical composition and arrangement of fillers answer why Tetric N-Ceram bulk fill (Ivoclar Vivadent) demonstrated more statistical significant differences in surface roughness values (less resistance to wear and surface roughness) compared to other two types of bulk fill resin composite. There was a clear correlation between surface roughness and chemical composition for all composite types and dentifrices used in the present study. In previous studies by Kanter et al. [38] and Mandikos et al. [39], they were concluded that composites which wear more showed increased surface roughness. This was in agreement with the findings of our study but was conflicting with the outcomes of the studies by Wang et al. [28] and Garcia et al. [15] where they concluded that there was no significant relationship between the degree of wear resistance of resin composite and their surface roughness.

\section{Conclusion}

Under limitation of the present study, the results revealed that chemical composition of bulk fill resin composites and abrasive materials incorporated within the dentifrices plays an important role in influencing the degree of surface roughness of bulk fill composite restorations. The degree of toothbrush abrasion depends on variety of factors such as type of resin composite, the chemistry and method of polymerization, type of toothpaste, and the nature of the toothbrush used. Further studies should be done to clarify the relation between wear resistance and surface roughness of different esthetic restorative materials.

\section{Recommendations}

Under limitation of the present study, the results revealed that:

1. Lacalut toothpaste abrades more with Filtek Bulk Fill then Tetric N-Ceram and finally Bulk Fill SDR so it is not recommended that patient of Filtek Bulk Fill composite restoration to use Lacalut toothpaste for rotary toothbrushing using medium type of toothbrush.

2. Crest 3D White toothpaste abrades more with Tetric N-Ceram then Bulk Fill SDR and finally Filtek Bulk Fill so it is not recommended that patient of Tetric $\mathrm{N}$-Ceram composite restoration to use Crest $3 \mathrm{D}$ White toothpaste for rotary toothbrushing using medium type of toothbrush.

3. BlanX toothpaste abrades more with Tetric $\mathrm{N}$-Ceram then Bulk Fill SDR and finally Filtek Bulk Fill so it is not recommended that patient of Tetric $\mathrm{N}$-Ceram composite restoration to use Crest $3 \mathrm{D}$ White toothpaste for rotary toothbrushing using medium type of toothbrush.

\section{References}

1. Nash RW, Lowe RA, Leinfelder K. Using packable composites for direct posterior placement. J Am Dent Assoc. 2001;132(8):1099104. https://doi.org/10.14219/jada.archive.2001.0334 PMid:11575016

2. Curtis AR, Shortall AC, Marquis PM, Palin WM. Water uptake and strength characteristics of a nano-filled resin-based composite. J Dent. 2008;36(3):186-93. https://doi.org/10.1016/j. jdent.2007.11.015

PMid:18237839

3. Ali S, Iqbal K, Asmat M, Farooq I, Khan AM, Alam MK. Dental resin composite restoration practices amongst general dental practitioners of Karachi, Pakistan. World J Dent. 2019;10(2):129134. https://doi.org/10.5005/jp-journals-10015-1618

4. Furness A, Tadros MY, Looney SW, Rueggeberg FA. Effect of bulk/incremental fill on internal gap formation of bulkfill composites. J Dent. 2014;42(4):439-49. https://doi. org/10.1016/j.jdent.2014.01.005

PMid:24480086

5. Ilie N, Hickel R. Investigations on mechanical behavior of denta composites. Clin Oral Investig. 2009;13(4):427-38. https://doi. org/10.1007/s00784-009-0258-4 
PMid:19242739

6. Abouelleil H, Pradelle N, Villat C, Attik N, Colon P, Grosgogeat B. Comparison of mechanical properties of a new fiber reinforced composite and bulk filling composites. Restor Dent Endod. 2015;40(4):262-70. https://doi.org/10.5395/rde.2015.40.4.262 PMid:26587411

7. Moorthy A, Hogg $\mathrm{CH}$, Dowling AH, Grufferty BF, Benetti AR, Fleming GJ. Cuspal deflection and microleakage in premolar teeth restored with bulk-fill flowable resin-based composite base materials. J Dent. 2012;40(6):500-5. https://doi.org/10.1016/j. jdent.2012.02.015

PMid:22390980

8. Walter R. Critical appraisal: Bulk-fill flowable composite resins. J Esthet Restor Dent. 2013;25(1):72-6. https://doi.org/10.1111/ jerd.12011

PMid:23374413

9. Farooq I, Ali S, Siddiqui IA, Al-Khalifa KS, Al-Hariri M. Influence of thymoquinone exposure on the micro-hardness of dental enamel an in vitro study. Eur J Dent 2019;13(3):318-22. https:// doi.org/10.1055/s-0039-1697117

PMid:31618784

10. Alfaroukh R, Elembaby A, Almas K, Ali S. Oral Biofilm formation and retention on commonly used dental materials: An update. Trop Dent J. 2018;41(164):28-34.

11. Momoi $\mathrm{Y}$, Hirosaki $\mathrm{K}$, Kohno A, McCabe JF. In vitro toothbrushdentifrice abrasion of resin-modified glass ionomers. Dent Mater. 1997;13(2):82-8. https://doi.org/10.1016/ s0109-5641(97)80016-4

PMid:9467309

12. Krejci I, Lutz F, Boretti R. Resin composite polishing filling the gaps. Quintessence Int. 1999;30(7):490-5. PMid:10635262

13. Paravina RD, Roeder L, Lu H, Vogel K, Powers JM. Effect of finishing and polishing procedures on surface roughness, gloss and color of resin-based composites. Am J Dent. 2004;17(4):262-6.

PMid: 15478488

14. Yap AU, Lye KW, Sau CW. Surface characteristics of tooth colored restoratives polished utilizing different polishing systems. Oper Dent. 1997;22(6):260-5.

PMid:9610323

15. Garcia FC, Wang L, D'Alpino PH, Souza JB, Araujo PA, Mondelli RF. Evaluation of the roughness and mass loss of the flowable composites after simulated tooth brushing abrasion. Braz Oral Res. 2004;18(2):156-61. https://doi.org/10.1590/ s1806-83242004000200012

16. Yap AU, Wu SS, Chelvan S, Tan ES. Effect of hygiene maintenance procedures on surface roughness of composite restoratives. Oper Dent. 2005;30(1):99-104.

PMid:15765964

17. Farooq I, Ali S, Al-Khalifa KS, Alhooshani K. Total and soluble fluoride concentration present in various commercial brands of children toothpastes available in Saudi Arabia a pilot study. Saudi Dent J. 2018;30(2):161-5. https://doi.org/10.1016/j. sdentj.2018.01.001

PMid:29628740

18. Teixeira EC, Thompson JL, Piascik JR, Thompson JY. In vitro toothbrush-dentifrice abrasion of two restorative composites. J Esthet Restor Dent. 2005;17(3):172-80. https://doi. org/10.1111/j.1708-8240.2005.tb00109.x PMid:15996389

19. Amaral CM, Rodrigues JA, Erhardt MC, Araujo MW, Marchi GM, Heymann HO, et al. Effect of whitening dentifrices on the superficial roughness of esthetic restorative materials. J Esthet Restor Dent. 2006;18(2):102-8. https://doi. org/10.2310/6130.2006.00017_1.x

PMid:16519874

20. Cury JA, Rosing CK, Tenuta LM. Are dentifrices all the same? Int J Braz Dent. 2010;6:254-6.

21. Wiegand A, Schlueter N. The role of oral hygiene: Does tooth brushing harm? Monogr Oral Sci. 2014;25:215-9.

PMid:24993269

22. Kodaka T, Kuroiwa M, Kuroiwa M, Okumura J, Mori R, Hirasawa $S$, et al. Effects of brushing with a dentifrice for sensitive teeth on tubule occlusion and abrasion of dentin. J Electron Microsc (Tokyo). 2001;50(1):57-64. https://doi. org/10.1093/jmicro/50.1.57

PMid:11291961

23. De Menezes M, Turssi CP, Hara AT, Messias DC, Serra MC. Abrasion of eroded root dentine brushed with different toothpastes. Clin Oral Investig. 2004;8(3):151-5. https://doi. org/10.1007/s00784-004-0262-7

PMid: 15146320

24. Liljeborg A, Tellefsen G, Johannsen G. The use of a profilometer for both quantitative and qualitative measurements of toothpaste abrasivity. Int J Dent Hyg. 2010;8(3):237-43. https:// doi.org/10.1111/j.1601-5037.2009.00433.x

PMid:20624195

25. Dietschi D, Campanile G, Holz J, Meyer JM. Comparison of the color stability of ten new-generation composites: An in vitro study. Dent Mater. 1994;10:353-62. https://doi. org/10.1016/0109-5641(94)90059-0

PMid:7498599

26. Sarac D, Sarac YS, Kulunk S, Ural C, Kulunk T. The effect of polishing techniques on the surface roughness and color change of composite resins. J Prosthet Dent. 2006;96:33-40. https://doi.org/10.1016/j.prosdent.2006.04.012 PMid:16872928

27. Janda R, Roulet JF, Kaminsky M, Steffi n G, Latta M. Color stability of resin matrix restorative materials as a function of the method of light activation. Eur J Oral Sci. 2004;112:280-5. https://doi.org/10.1111/j.1600-0722.2004.00125.x PMid:15154928

28. Wang L, Garcia FC, de Araujo PA, Franco EB, Mondelli RF. Wear resistance of packable resin composites after simulated tooth brushing test. J Esthet Restor Dent. 2004;16(5):303-14. https://doi.org/10.1111/j.1708-8240.2004.tb00058.x PMid:15726799

29. Moraes RR, Ddos SR, Klumb MM, Brandt WC, CorrerSobrinho L, Bueno M. In vitro tooth brushing abrasion of dental resin composites: Packable, microhybrid, nanohybrid and microfilled materials. Braz Oral Res. 2008;22(2):112-8. https:// doi.org/10.1590/s1806-83242008000200004 PMid:18622479

30. Oliveira GU, Mondelli RF, Charantola Rodrigues M, Franco EB, Ishikiriama SK, et al. Impact of filler size and distribution on roughness and wear of composite resin after simulated tooth brushing. J Appl Oral Sci. 2012;20(5):510-6. https://doi. org/10.1590/s1678-77572012000500003

PMid:23138735

31. Turssi CP, Hara AT, de Magalhaes CS, Serra MC, Rodrigues AL Jr. Influence of storage regime prior to abrasion on surface topography of restorative materials. J Biomed Mater Res B Appl Biomater. 2003;65(2):227-32. https://doi. org/10.1002/jbm.b.10005 PMid:12687714

32. Suzuki $\mathrm{T}$, Kyoizumi $\mathrm{H}$, Araki $\mathrm{Y}$, Finger WJ, Kanehira $\mathrm{M}$. Toothbrush abrasion of resin composites with different 
filler concepts. World J Dent. 2012;3(2):184-93. https://doi. org/10.5005/jp-journals-10015-1154

33. Mitra SB, Wu D, Holmes BN. An application of nanotechnology in advanced dental materials. J Am Dent Assoc. 2003;134(10):1382-90.

PMid:14620019

34. Turssi CP, de Magalhaes CS, Serra MC, Junior AL. Surface roughness assessment of resin-based materials during brushing preceded by $\mathrm{pH}$-cycling simulations. Oper Dent. 2001;26(6):576-84 . PMid:11699181

35. Bollen CM, Lambrechts $\mathrm{P}$, Quirynen M. Comparison of surface roughness of oral hard materials to the threshold surface roughness for bacterial plaque retention: A review of the literature. Dent Mater. 1997;13(4):258-69. https://doi. org/10.1016/s0109-5641(97)80038-3

PMid:11696906

36. Quirynen M, Bollen CM. The influence of surface roughness and surface-free energy on supra and subgingival plaque formation in man. A review of the literature. J Clin Periodontol. 1995;22(1):114. https://doi.org/10.1111/j.1600-051x.1995.tb01765.

PMid:7706534

37. Jones CS, Billington RW, Pearson GJ. The in vivo perception of roughness of restorations. Br Dent J. 2004;195(1):42-5.

PMid:14966503

38. Kanter J, Koski RE, Martin D. The relationship of weight loss to surface roughness of composite resins from simulated toothbrushing. J Prosthet Dent. 1982;47(5):505-13. https://doi. org/10.1016/0022-3913(82)90300-6

PMid:6211543

39. Mandikos MN, McGivney GP, Davis E, Bush PJ, Carter JM. A comparison of the wear resistance and hardness of indirect composite resins. J Prosthet Dent. 2001;85(4):386-95. https:// doi.org/10.1067/mpr.2001.114267

PMid:11319537 